\title{
Separation of the gluconeogenic and mitochondrial functions of PGC-1 $\alpha$ through S6 kinase
}

\author{
Yaniv Lustig, ${ }^{1}$ Jorge L. Ruas, ${ }_{1}^{1}$ Jennifer L. Estall, ${ }^{1}$ James C. Lo, ${ }^{1}$ Srikripa Devarakonda, ${ }^{1}$ Dina Laznik, ${ }^{1}$ \\ Jang Hyun Choi, ${ }^{1}$ Hiraku Ono, ${ }^{2}$ Jesper V. Olsen, ${ }^{3}$ and Bruce M. Spiegelman ${ }^{1,4}$ \\ ${ }^{1}$ Department of Cell Biology, Dana-Farber Cancer Institute, Harvard Medical School, Boston, Massachusetts 02115, USA; \\ ${ }^{2}$ Department of Internal Medicine, Division of Endo/Diabetes, Saitama Medical University, Saitama 350-0495, Japan; \\ ${ }^{3}$ Department of Proteomics, Novo Nordisk Foundation Center for Protein Research, Faculty of Health Sciences, University of \\ Copenhagen, Copenhagen DK-2200, Denmark
}

PGC-1 $\alpha$ is a transcriptional coactivator that powerfully regulates many pathways linked to energy homeostasis. Specifically, PGC-1 $\alpha$ controls mitochondrial biogenesis in most tissues but also initiates important tissue-specific functions, including fiber type switching in skeletal muscle and gluconeogenesis and fatty acid oxidation in the liver. We show here that S6 kinase, activated in the liver upon feeding, can phosphorylate PGC-1 $\alpha$ directly on two sites within its arginine/serine-rich (RS) domain. This phosphorylation significantly attenuates the ability of PGC$1 \alpha$ to turn on genes of gluconeogenesis in cultured hepatocytes and in vivo, while leaving the functions of PGC-1 $\alpha$ as an activator of mitochondrial and fatty acid oxidation genes completely intact. These phosphorylations interfere with the ability of PGC-1 $\alpha$ to bind to $\mathrm{HNF} 4 \alpha$, a transcription factor required for gluconeogenesis, while leaving undisturbed the interactions of PGC-1 $\alpha$ with ERR $\alpha$ and PPAR $\alpha$, factors important for mitochondrial biogenesis and fatty acid oxidation. These data illustrate that S6 kinase can modify PGC-1 $\alpha$ and thus allow molecular dissection of its functions, providing metabolic flexibility needed for dietary adaptation.

[Keywords: PGC-1 $\alpha$; gluconeogenesis; liver; S6K1]

Supplemental material is available for this article.

Received March 29, 2011; revised version accepted May 10, 2011.

The transcriptional coactivator PGC-1 $\alpha$ regulates many metabolic programs, especially those related to oxidative metabolism (Wu et al. 1999). First identified as a coactivator of PPAR $\gamma$ in brown fat-mediated thermogenesis (Puigserver et al. 1998), PGC-1 $\alpha$ is now known to interact with many nuclear receptors and other transcription factors outside of this family (Knutti and Kralli 2001; Lin et al. 2005; Finck and Kelly 2006). PGC-1 $\alpha$ and its close homolog, PGC1 $\beta$, are critical for mitochondrial biogenesis and mitochondrial gene expression in various tissues $\mathrm{Wu}$ et al. 1999; Mootha et al. 2004; Schreiber et al. 2004). They achieve this through physical interactions with ERR $\alpha$, NRF1, and NRF2 (GABP) (Wu et al. 1999; Mootha et al. 2004; Schreiber et al. 2004). Mice lacking PGC-1 $\alpha$ or PGC1 $\beta$ (or both) have a deficiency in mitochondria and adaptive oxidative metabolism (Lin et al. 2004; Leone et al. 2005; Lelliott et al. 2006; Vianna et al. 2006; Zechner et al. 2010).

${ }^{4}$ Corresponding author.

E-mail bruce_spiegelman@dfci.harvard.edu.

Article published online ahead of print. Article and publication date are online at http://www.genesdev.org/cgi/doi/10.1101/gad.2054711.
In addition to mitochondrial biogenesis, PGC- $1 \alpha$ activates the expression of other genes that are part of broader programs associated with mitochondrial function in a specific tissue (Lin et al. 2005). For example, PGC-1 $\alpha$ is induced in skeletal muscle with exercise and stimulates expression of genes involved in fiber type switching, angiogenesis, and fatty acid oxidation (Vega et al. 2000; Baar et al. 2002; Lin et al. 2002; Norrbom et al. 2004; Koves et al. 2005; Arany et al. 2008). In the liver, PGC- $1 \alpha$ is strongly induced in fasting and turns on the gene programs of gluconeogenesis, heme biosynthesis, and fatty acid oxidation. This occurs through coactivation of hepatic $\mathrm{ERR} \alpha, \mathrm{NRF} 1, \mathrm{NRF} 2, \mathrm{PPAR} \alpha, \mathrm{HNF} 4 \alpha$, and FOXO1 (Herzig et al. 2001; Yoon et al. 2001; Puigserver et al. 2003; Rhee et al. 2003; Koo et al. 2004; Handschin et al. 2005; Wu et al. 2009). Gluconeogenic gene expression driven by PGC- $1 \alpha$ has a nearly absolute genetic requirement for $\mathrm{HNF} 4 \alpha$ and FOXO1, liver-enriched transcription factors (Puigserver et al. 2003; Rhee et al. 2003).

Coordination of these large gene sets, which are often functionally linked, must have distinct advantages for the organism. For example, coordination of genes within linked pathways can accelerate the overall output of a final 
product, such as glucose in the case of the gluconeogenic program (Spiegelman and Heinrich 2004). Coordination of the induction of many genes within complex pathways can also minimize the buildup of metabolic intermediates that could be toxic, such as many of the pathogenic intermediates generated in the heme biosynthetic system (Ajioka et al. 2006). High-level regulation through coactivation of many transcription factors makes sense kinetically, but adaptations to certain environmental states are likely to require the uncoupling of certain regulatory functions. For example, while the normal fasted state may indeed benefit from the coordination of mitochondrial electron transport with gluconeogenesis and fatty acid oxidation, it is easy to imagine that high caloric intake, especially with diets rich in both fats and carbohydrates, may require ramping up fatty acid oxidation and electron transport in the mitochondria without coordinately inducing gluconeogenesis.

Several mechanisms to increase or decrease the total amount and activity of PGC- $1 \alpha$ are now known. Activation pathways include deacetylation of the PGC-1 $\alpha$ protein by SirT1 (Rodgers et al. 2005) and phosphorylation by the p38 MAP kinase (Puigserver et al. 2001). Hormones that increase intracellular cAMP or calcium all generally increase the expression of PGC-1 $\alpha$ (Wu et al. 2002). Inhibition of PGC-1 $\alpha$ can occur through protein phosphorylation by AKT (Li et al. 2007) and Clk2 (Rodgers et al. 2010) and/or protein acetylation by GCN5 (Lerin et al. 2006). Direct binding of the corepressor p160MBP also represses PGC-1 $\alpha$ activity (Fan et al. 2004). However, no studies to date have described the mechanisms whereby the multiple functions of PGC- $1 \alpha$ can be differentially regulated within a single cell type.

In this study, we found that $\mathrm{S} 6 \mathrm{~K} 1$, a serine/threonine kinase that mediates nutrient and insulin signals, directly phosphorylates PGC-1 $\alpha$ at two sites in hepatocytes. The phosphorylated PGC- $1 \alpha$ is largely unaltered in its ability to increase the expression of genes related to the mitochondrial electron transport system and the $\beta$-oxidation of fatty acids. However, this modified form of the protein has a greatly reduced ability to activate the gene program of gluconeogenesis and has reduced binding to HNF4 $\alpha$. Thus, we identified a mechanism by which the complex genetic and physiological programs driven by PGC- $1 \alpha$ in the liver can be differentially regulated.

\section{Results}

S6K1 directly phosphorylates PGC-1 $\alpha$ on Ser 568 and Ser 572

PGC-1 $\alpha$ regulates mitochondrial gene expression, fatty acid oxidation, and gluconeogenesis in the liver (Herzig et al. 2001; Yoon et al. 2001; Puigserver et al. 2003; Rodgers et al. 2005, 2010; Lerin et al. 2006; Li et al. 2007). An open question, however, is whether the many PGC- $1 \alpha$ functions can be differentially regulated in response to changing metabolic conditions (i.e., fasting vs. feeding). To address this, we examined post-translational modifications of the PGC-1 $\alpha$ protein in primary hepatocytes in a serum-con- taining medium. Murine hepatocytes were infected with adenoviral vectors expressing PGC-1 $\alpha$; the protein was then immunoprecipitated and studied for phosphorylations. Two novel phosphorylations-at Ser 568 and Ser 572 in the arginine/serine-rich (RS) domain of PGC$1 \alpha$-were found by mass spectrometry (data not shown). The sequences of both of these two sites conform to the consensus motif Arg-x-Arg-X-x-pSer/Thr (RxRxxpS/T, where $\mathrm{x}$ is any amino acid). Alignment of the PGC-1 $\alpha$ sequences among different species shows that the serines at 568 and 572 and the adjacent motifs are conserved across all vertebrates (Supplemental Fig. 1). Both S6K1 and AKT/PKB are members of the AGC family of protein kinases known to phosphorylate this consensus motif (Pearce et al. 2010). In addition, the consensus motif of PKA, Arg-x-x-pSer/Thr, also conforms to the sequence of the two identified sites. In order to identify the kinase or kinases that specifically phosphorylate Ser 568 and Ser 572 in PGC-1 $\alpha$, we preformed in vitro phosphorylation experiments using a recombinant-expressed PGC-1 $\alpha$ fragment corresponding to the RS domain of PGC-1 $\alpha$ (amino acids 551-635). Of the kinases listed above, only S6K1 directly phosphorylated the RS domain of PGC- $1 \alpha$ and was unable to phosphorylate the same fragment with alanine substitutions at amino acids 568 and 572 (Fig. 1A; Supplemental Fig. 2). This result indicates that S6K1 can specifically phosphorylate PGC-1 $\alpha$ at Ser 568 and Ser 572 in vitro.

In order to identify possible additional phosphorylation sites of S6K1 on PGC- $1 \alpha$, an in vitro kinase assay was performed using recombinant-expressed PGC- $1 \alpha$ fragments corresponding to the entire protein. In addition to the RS domain, relatively minor phosphorylations were also detected in the 200- to 400-amino-acid fragment of PGC- $1 \alpha$ (Fig. 1B).

We next wanted to determine whether the serines at 568 and 572 are indeed the major sites of phosphorylation by S6K1 in full-length PGC-1 $\alpha$, and the possible importance of the phosphorylations in the 200-400 domain. Flag-tagged full-length or mutant PGC-1 $\alpha$ in which Ser 568/572 were substituted to alanine was transfected into 293T cells. PGC-1 $\alpha$ was immunoprecipitated via the Flag epitope and subjected to an in vitro kinase assay with the S6K1 enzyme. Wild-type PGC-1 $\alpha$ was phosphorylated by S6K1, whereas the phosphorylation of the mutant PGC-1 $\alpha$ was only slightly above the background (Fig. 1C). This strongly suggests that Ser 568 and Ser 572 are indeed the major sites in PGC-1 $\alpha$ phosphorylated by S6K1. PGC-1 $\alpha$ was also phosphorylated by S6K1 in cells, since an anti-RxRxxpS motif antibody was able to detect phosphorylated PGC-1 $\alpha$ only in cells overexpressing both PGC-1 $\alpha$ and S6K1 (Fig. 1D).

We next studied the ability of S6K1 to phosphorylate PGC-1 $\alpha$ in a setting more dependent on a nutritional and physiological variable. Activation of mTORC1 and its downstream target, S6K1, is dependent on nutrient availability (Patti et al. 1998; Nobukuni et al. 2005). This pathway is largely independent on the type 1A PI 3-kinase and the AKT/PKB pathway (Nobukuni et al. 2005). Using an anti-RxRxxpS motif antibody, we were able to detect phosphorylated PGC-1 $\alpha$ in cells with forced expression of wild-type PGC- $1 \alpha$ only with the addition of amino acids 
Lustig et al.

A

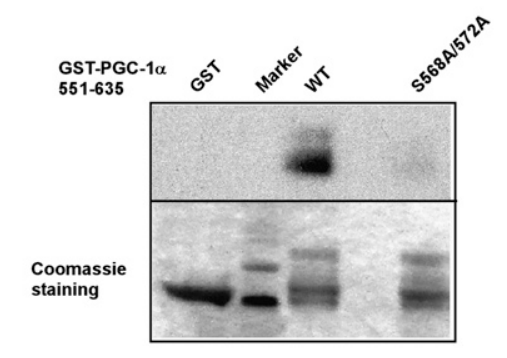

C

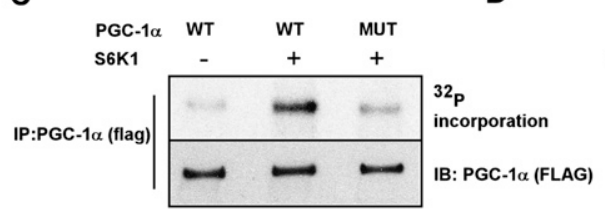

B

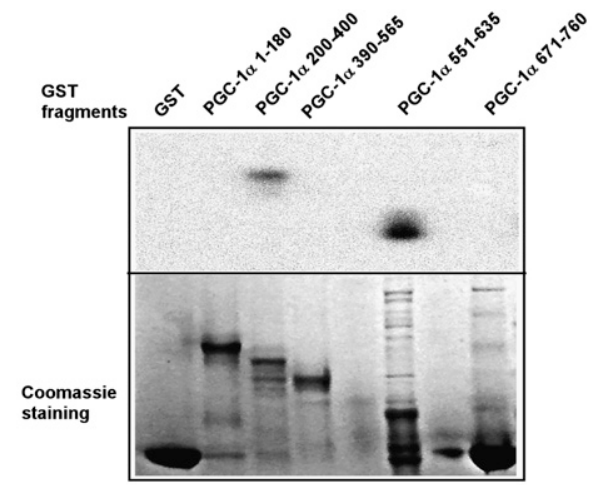

$\mathrm{E}$

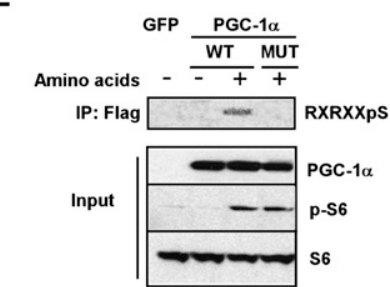

Figure 1. S6K1 phosphorylates PGC-1 $\alpha$ at Ser 568 and Ser 572. (A) Phosphorylation of PGC-1 $\alpha$ in vitro by S6K1. A purified recombinant wild-type GST-PGC-1 $\alpha$ fragment (amino acids 551-635) or a mutant PGC-1 $\alpha$ fragment with alanine substitutions at amino acids 568 and 572 were tested as substrates for recombinant-activated S6K1. (B) In vitro phosphorylation by S6K1 with different GST-PGC- $1 \alpha$ fragments, as indicated. $(C)$ Full-length PGC- $1 \alpha$ is phosphorylated by S6K1 in vitro. HEK293T cells were transfected with vectors expressing Flag-tagged full-length PGC-1 $\alpha$, wild type, or mutant. PGC-1 $\alpha$ was immunoprecipitated via the Flag epitope and was used in an in vitro protein kinase assay with S6K1. Protein levels were measured by probing with a polyclonal antibody against PGC-1 $\alpha$. (D) S6K1 phosphorylates PGC-1 $\alpha$ in cells. HEK293T cells were transfected with vectors expressing Flag-tagged PGC-1 $\alpha$ or GFP, with or without S6K1. Whole-cell extracts and Flag immunoprecipitates were subjected to Western blot analysis with the indicated antibodies. (E) Phosphorylation of PGC-1 $\alpha$ in hepatocytes by activation of S6K1. Primary mouse hepatocytes were infected with adenoviral vectors expressing Flag-tagged wild-type (WT) or mutant (MUT) PGC-1 $\alpha$ or GFP. Cells were treated overnight with serum and amino acid-free medium. Amino acids were added to the medium where indicated and cells were harvested $2 \mathrm{~h}$ later. Whole-cell extracts and Flag immunoprecipitates were subjected to Western blot analysis with antibodies as indicated.

to the medium. However, we were unable to detect phosphorylated PGC-1 $\alpha$ in cells expressing the mutant PGC-1 $\alpha$, even with the addition of amino acids (Fig. 1E). Taken together, these results indicate that S6K1 directly phosphorylates PGC-1 $\alpha$ both in vitro and in cells under a nutritional stimulus.

\section{The S6K1-mediated phosphorylation of PGC-1 $\alpha$ specifically regulates hepatic gluconeogenesis in primary hepatocytes}

To directly determine the effects of S6K1 phosphorylation on the transcriptional program driven by PGC-1 $\alpha$ in liver cells, primary hepatocytes were infected with adenoviral vectors expressing wild-type or mutant PGC-1 $\alpha$ or GFP as control. As expected (Vega et al. 2000; Yoon et al. 2001), forced expression of wild-type PGC-1 $\alpha$ induced the expression of mitochondrial, fatty acid oxidation, and gluconeogenic genes, compared with the GFP-expressing controls (Fig. 2A). Cells expressing the PGC-1 $\alpha$ mutant showed a similar induction of mitochondrial and fatty acid oxidation genes. However, the expression of the two key genes involved in gluconeogenesis-glucose-6-phosphatase (G6P) and phosphoenolpyruvate carboxykinase (PEPCK) - was dramatically higher in cells expressing the mutant PGC- $1 \alpha$ compared with the wild-type protein (Fig. $2 \mathrm{~A})$. The phosphorylation of PGC-1 $\alpha$ at these sites did not affect the apparent stability of the mRNA or protein, as adenovirus-mediated expression of wild-type and mutant PGC-1 $\alpha$ in primary hepatocytes resulted in similar protein (Fig. 2B) and mRNA (Fig. 2A) levels. The elevated induction of gluconeogenic genes observed in mutant PGC$1 \alpha$-expressing cells was also accompanied by increased glucose output from the primary hepatocytes (Fig. 2C). These results indicate that phosphorylation of PGC-1 $\alpha$ at these two sites impacts the function of PGC- $1 \alpha$, specifically on the gluconeogenic pathway, without detectably affecting other pathways regulated by PGC- $1 \alpha$, such as the gene programs of mitochondrial electron transport and fatty acid oxidation.

\section{Alteration of S6K1 signaling specifically modulates gluconeogenic gene expression}

S6K1 is an important protein kinase implicated in control of the fasting and refeeding response in the liver (Um et al. 2006). To gain a clearer understanding of how S6K1 signaling affects hepatic gene transcription within the context of PGC- $1 \alpha$ activation, we modulated S6K1 activity in primary hepatocytes. PGC-1 $\alpha$ or GFP were first 
A

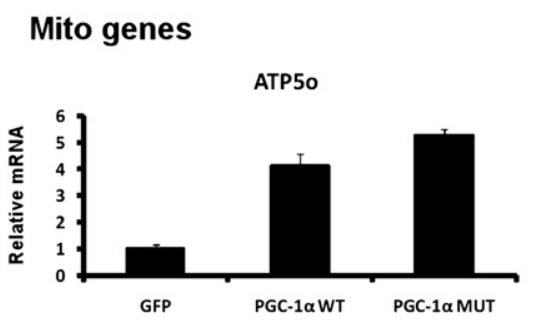

FAO genes

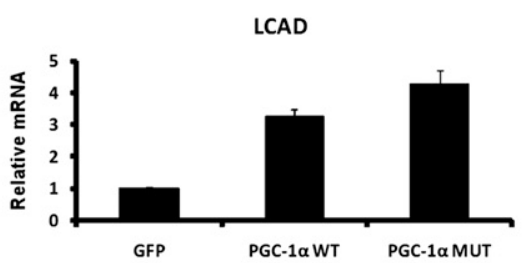

Gluconeogenic genes

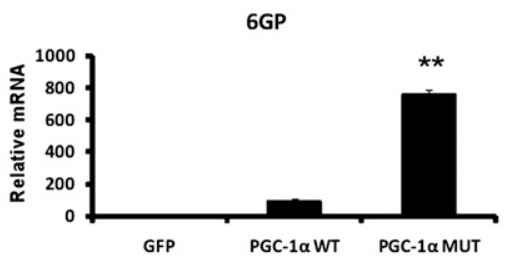

B

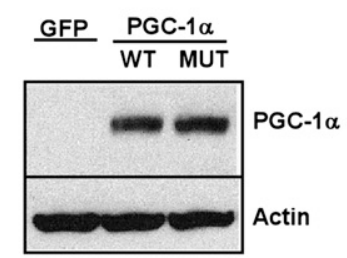

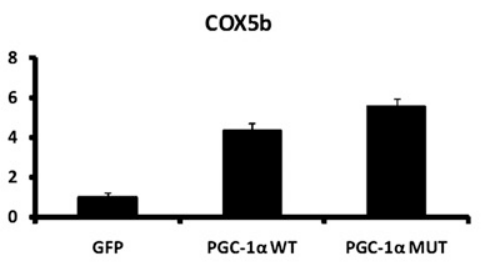
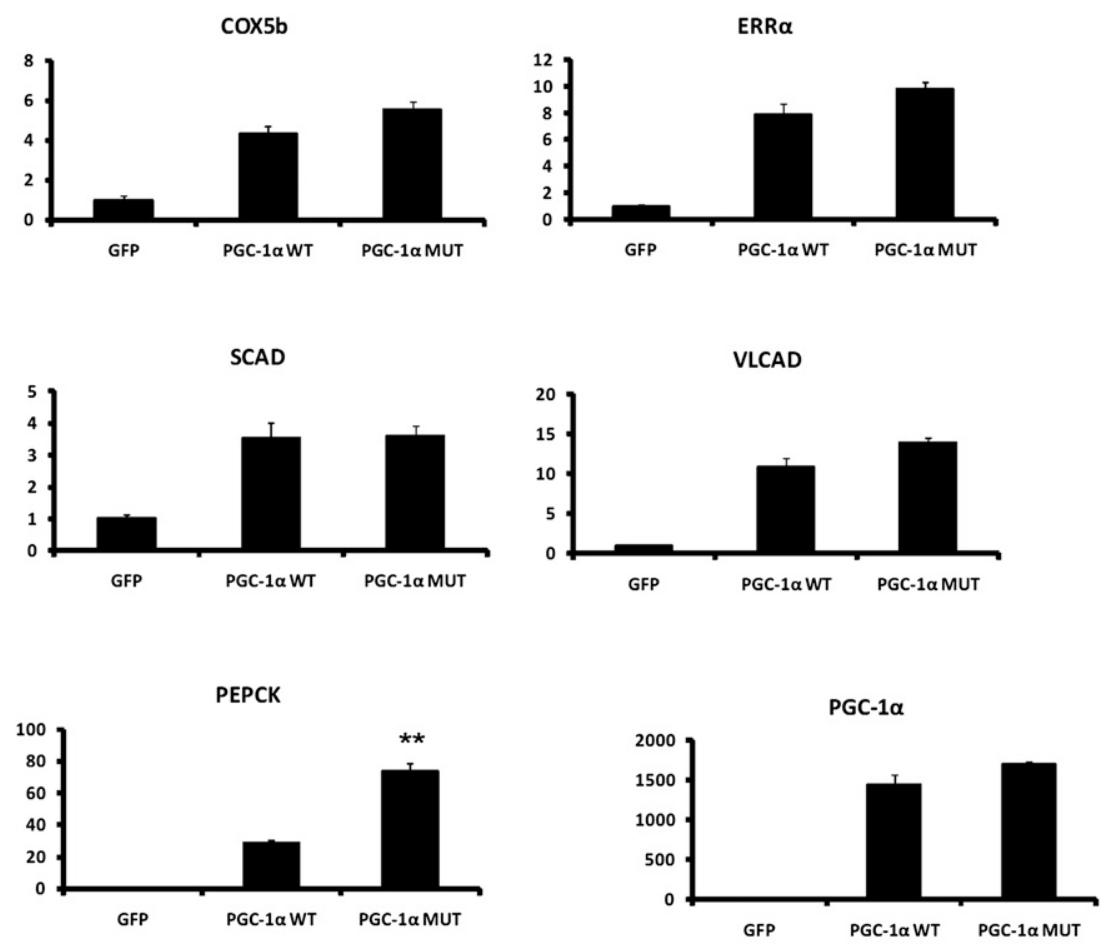

C

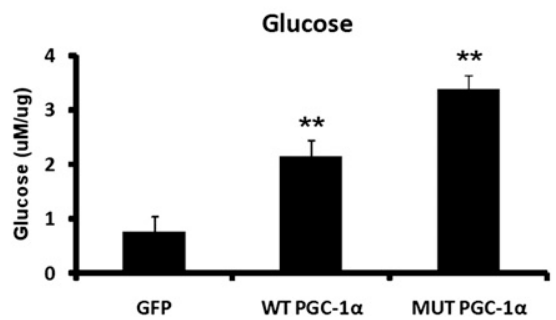

Figure 2. Mutations of the S6K1 phosphorylation sites in PGC-1 $\alpha$ induces gluconeogenic genes in primary hepatocytes. Primary hepatocytes were infected with adenovirus expressing wild-type PGC-1 $\alpha(\mathrm{WT})$, mutant PGC-1 $\alpha$ (MUT), or GFP as control. $(A)$ Total RNA was subjected to quantitative RT-PCR (qRT-PCR) analysis for the indicated genes. (B) Protein samples were subjected to Western blot analysis with PGC- $1 \alpha$ and actin antibodies. $(C)$ Cells were incubated in phenol red-free, glucose-free DMEM for $3 \mathrm{~h}$ and glucose levels were measured. $\left(^{\star \star}\right) P<0.01$.

expressed in primary hepatocytes with or without the addition of rapamycin, an mTOR and S6K1 inhibitor (Brown et al. 1994; Pearson et al. 1995). As expected, rapamycin blocked S6K1 activity in cells expressing either PGC-1 $\alpha$ or GFP, as evident by the ablation of phosphorylation of S6, a direct downstream target of S6K1 (Fig. 3A; Flotow and Thomas 1992). Under these basal conditions, endogenous PGC-1 $\alpha$ levels are extremely low in primary hepatocytes. Rapamycin treatment did not significantly change expression levels of genes of mitochondrial electron transport, fatty acid oxidation, and gluconeogenesis in the GFPexpressing cells. In cells expressing PGC-1 $\alpha$, however, blocking S6K1 activity with rapamycin significantly induced the expression of the gluconeogenic genes G6P and PEPCK. Rapamycin treatment did not significantly change the expression of genes involved in the fatty acid oxidation or mitochondrial biogenesis pathways (Fig. 3B). A similar result was observed by specifically blocking S6K1 activation in primary hepatocytes using an adenovirus expressing a dominant-negative allele of $S 6 K 1$ (S6K1 DN) (Supplemental Fig. 3).

We induced S6K1 activity by introducing a constitutively active S6K1 (S6K1ca) into primary hepatocytes that also had forced expression of GFP or PGC-1 $\alpha$. Expression of S6K1ca induced S6K1 activity and phosphorylation of S6 (Fig. 3C). As with rapamycin treatment, no significant change was observed in the transcription of mitochondrial, fatty acid oxidation, and gluconeogenic genes in the GFPexpressing cells when S6K1 was activated. However, S6K1 activation significantly reduced the expression of the 
Lustig et al.
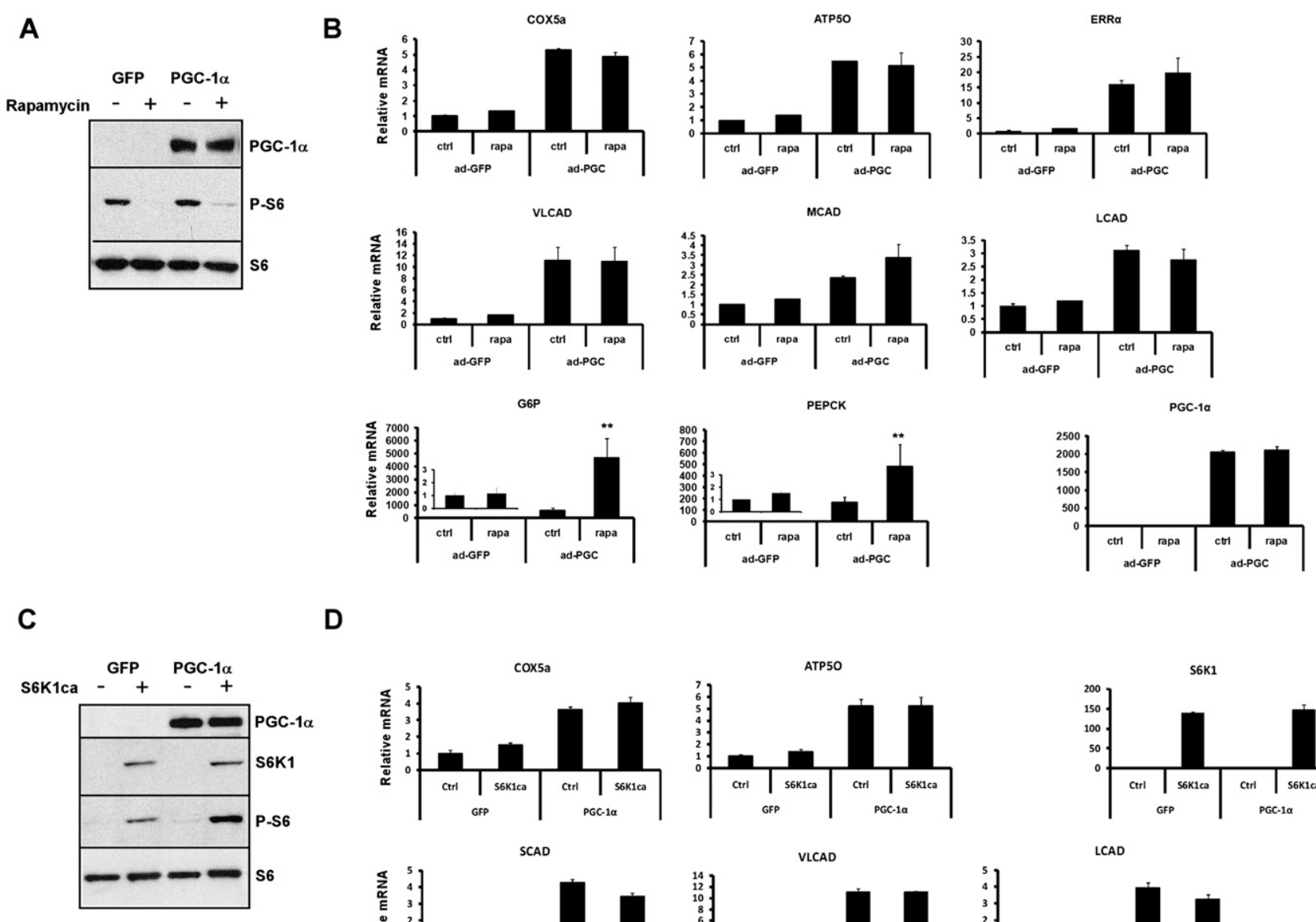

D
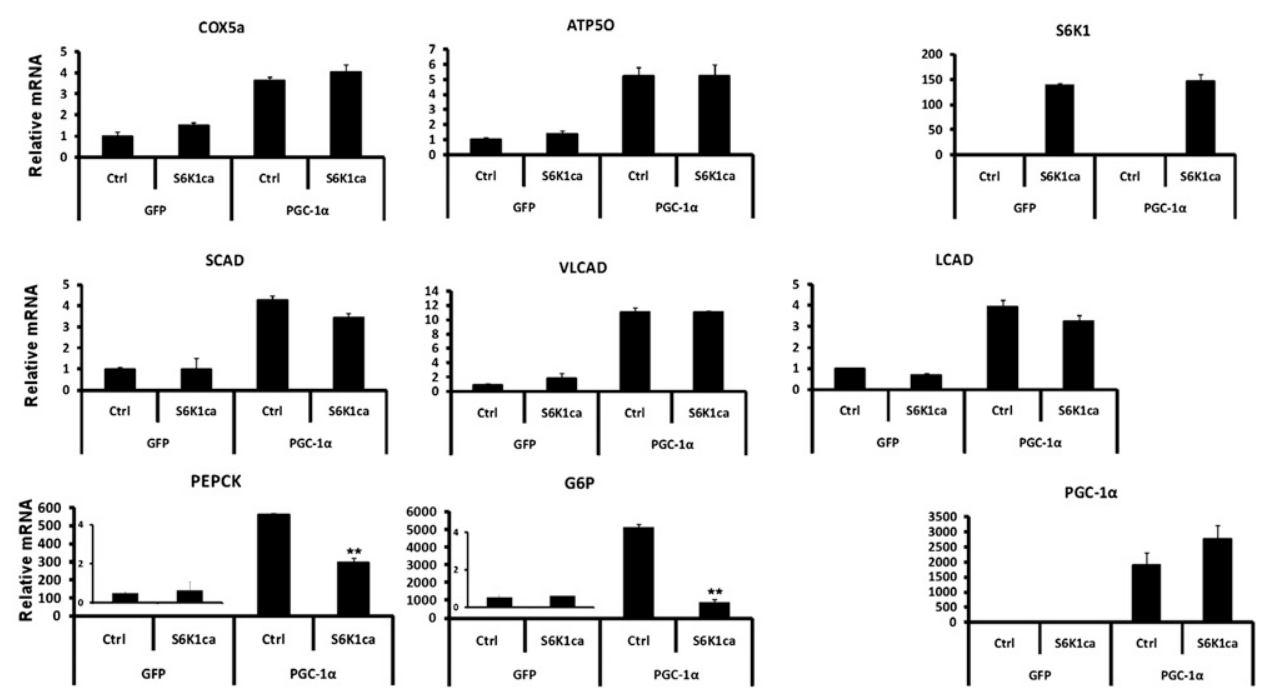

Figure 3. Gluconeogenic gene expression is modulated by S6K1. (A) Gluconeogenic genes expression is induced when S6K1 signaling is blocked. Primary hepatocytes were infected with adenoviral vectors expressing wild-type PGC-1 $\alpha$ or GFP. Cells were treated for $8 \mathrm{~h}$ with $20 \mathrm{nM}$ rapamycin where indicated (rapa), and whole-cell lysate was subjected to Western blot analysis with the indicated antibodies. $(B)$ Total RNA was extracted from primary hepatocytes infected and treated as in $A$ and was subjected to qRT-PCR analysis for the indicated genes. $(C, D)$ Gluconeogenic gene expression is attenuated when S6K1 signaling is induced. Primary hepatocytes were infected with adenoviral vectors expressing wild-type PGC-1 $\alpha$ or GFP with or without a S6K1ca adenovirus. Cells were treated for $4 \mathrm{~h}$ with serum and amino acid-free medium before total RNA and protein were extracted. Protein samples were subjected to Western blot analysis $(C)$ and total RNA was subjected to qRT-PCR analysis $(D)$ for the indicated genes. $\left(^{\star \star}\right) P<0.01$.

gluconeogenic genes in cells expressing PGC-1 $\alpha$. Activation of S6K1 did not change the expression levels of mitochondrial and fatty acid oxidation mRNAs (Fig. 3D).

To ask whether S6K1 regulates the gluconeogenic program by phosphorylating Ser $568 / 572$ of PGC- $1 \alpha$, we expressed both wild-type and mutant PGC-1 $\alpha$ in primary hepatocytes with or without rapamycin. As seen in Figure 4 , the mutant PGC-1 $\alpha$ was unresponsive to S6K1 signaling, and, subsequently, blocking S6K1 activity in cells expressing the mutant did not further increase expression of the gluconeogenic program. These data strongly suggest that modulation of S6K1 specifically affects the gluconeogenic pathway in hepatocytes without affecting other pathways known to be activated by PGC- $1 \alpha$; this effect on the gluconeogenic genes is mediated by S6K1 phosphorylation of Ser $568 / 572$ of PGC- $1 \alpha$.

\section{S6K1 action on the gluconeogenic program is genetically dependent on PGC-1 $\alpha$}

Treatment of primary hepatocytes with an agent such as forskolin, which raises cAMP, can mimic the actions of 

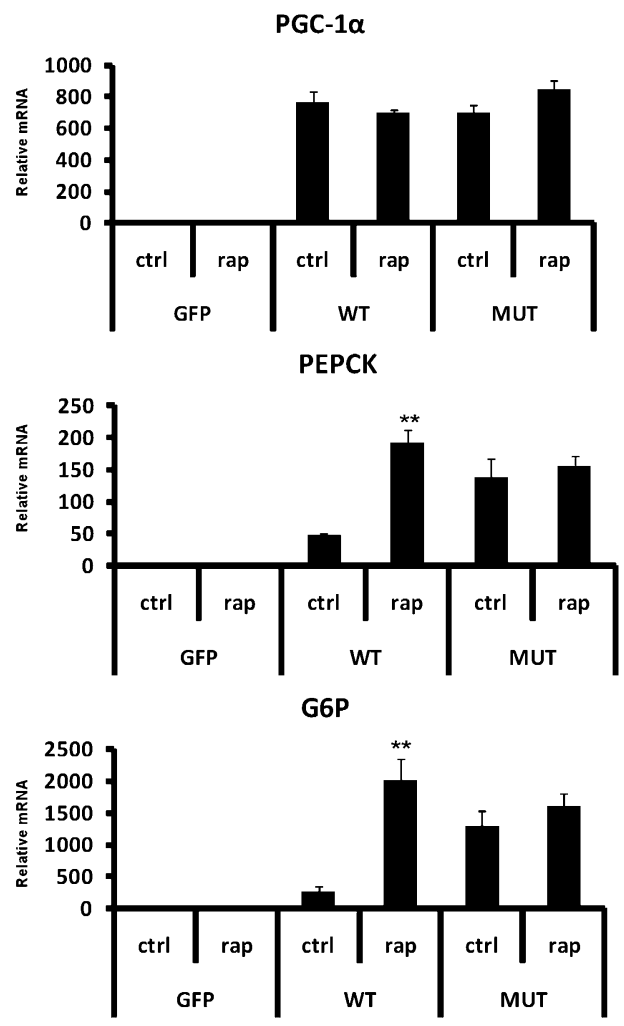

Figure 4. S6K1 phosphorylation of PGC- $1 \alpha$ at Ser 568/572 regulates gluconeogenic genes expression. Primary hepatocytes infected with wild-type (WT) and mutant (MUT) PGC-1 $\alpha$ - or GFPexpressing adenoviruses were treated with $20 \mathrm{nM}$ rapamycin (rap) for $8 \mathrm{~h}$ where indicated. Total RNA was extracted and subjected to qRT-PCR analysis for the indicated genes. $\left({ }^{\star \star}\right) P<0.01$.

glucagon in fasting. Part of this critical physiological response is through inducing the fasting/gluconeogenic gene program PEPCK, G6P, and PGC-1 $\alpha$ (Yoon et al. 2001). The induction of PGC-1 $\alpha$ by forskolin is largely mediated through an increase in mRNA levels (Yoon et al. 2001). We thus examined the effect of blocking S6K1 action on the levels and activity of endogenous PGC-1 $\alpha$ and its downstream targets in response to forskolin. Consistent with findings described above, rapamycin treatment did not change the expression levels of the gluconeogenic genes, whereas forskolin significantly increased the expression levels of both G6P and PEPCK mRNAs. However, the treatments with forskolin and rapamycin together showed a synergistic effect on the expression levels of both gluconeogenic genes (Fig. 5A). This synergistic effect on gluconeogenic gene expression was likely due to an increased activity of PGC-1 $\alpha$ and not an additional increase in PGC$1 \alpha$ expression level, as treatment with forskolin alone or both forskolin and rapamycin resulted in similar levels of PGC-1 $\alpha$ protein (Fig. 5B). These results suggest that blocking S6K1 signaling within a cellular context mimicking nutrient deprivation specifically increases PGC- $1 \alpha$ actions on the gluconeogenic pathway.

To address the requirements for PGC- $1 \alpha$ in this response more directly, PGC-1 $\alpha$ was knocked down in primary hepatocytes using a very effective shRNA described previously (Estall et al. 2009). Both mRNA (Fig. $5 \mathrm{C}$ ) and protein levels (data not shown) of PGC-1 $\alpha$ were significantly reduced in cells infected with an adenoviral vector expressing shPGC- $1 \alpha$. Forskolin induction of PGC- $1 \alpha$ and the gluconeogenic genes G6P and PEPCK was blunted upon reduction of PGC1 $\alpha$ (Fig. 5C). Importantly, treatment with rapamycin and forskolin together did not further increase gluconeogenic gene expression; furthermore, the synergistic effect seen in the control cells was completely blocked (Fig. 5C). Taken together, these results show that S6K1 modification of the gluconeogenic pathway is dependent on PGC- $1 \alpha$ activity.

\section{Mutations of the S6K1-mediated phosphorylation of $P G C-1 \alpha$ preferentially affects gluconeogenesis in vivo}

To ask whether the physiological programs driven by PGC-1 $\alpha$ are differentially regulated by S6K1 in vivo, we injected adenoviral vectors expressing wild-type or mutant PGC-1 $\alpha$ or GFP intravenously into mice; this technique results in targeted expression of proteins in the liver. In order to dynamically fine-tune the programs controlled by PGC-1 $\alpha$, we expressed relatively moderate levels of this coactivator. Protein levels of both wild-type and mutant PGC-1 $\alpha$ were similar $5 \mathrm{~d}$ after injection (Fig. 6A). After $22 \mathrm{~h}$ of fasting, the mice injected with wild-type PGC- $1 \alpha$ vectors showed a modest increase in mitochondrial, fatty acid oxidation, and gluconeogenic gene expression compared with the GFP-expressing controls (Fig. 6B). As shown previously (Rodgers and Puigserver 2007), this modest increase in gluconeogenic gene expression in the fasted state is not enough to cause a detectable increase in glucose (Fig. 6C) or insulin (Fig. 6D) levels. Mice injected with vectors expressing the mutant PGC- $1 \alpha$ showed a similarly modest increase in both fatty acid oxidation and mitochondrial biogenesis genes. However, mice expressing mutant PGC-1 $\alpha$ showed much greater induction of the gluconeogenic genes G6Pase and PEPCK (Fig. 6B). Fasting glucose levels increased significantly above those in mice expressing wild-type PGC- $1 \alpha$ or GFP (Fig. 6C). Fasting insulin levels were also trending upward, although this did not reach statistical significance (Fig. 6D). These results indicate that the modification of PGC- $1 \alpha$ on the S6K1 sites differentially regulates the gluconeogenic program in vivo. S6K1 phosphorylation of PGC-1 $\alpha$ reduces binding
to $H N F 4 \alpha$ but not to FOXO1, PPAR $\alpha$, or ERR $\alpha$

PGC1- $\alpha$ is a coactivator and functions through binding to specific transcription factors. The fasting response in the liver has been studied extensively, and PGC-1 $\alpha$ appears to have critical interactions with $\mathrm{HNF} 4 \alpha$, FOXO1, $\operatorname{ERR} \alpha$, and PPAR $\alpha$ (Herzig et al. 2001; Yoon et al. 2001; Puigserver et al. 2003; Rhee et al. 2003; Koo et al. 2004; Handschin et al. 2005; Wu et al. 2009). Since the nuclear receptor $\mathrm{HNF} 4 \alpha$ is a critical component of PGC- $1 \alpha$-mediated gluconeogenesis (Yoon et al. 2001; Rhee et al. 2003), the binding of PGC- $1 \alpha$ to HNF4 $\alpha$ was studied in HEK293T 
Lustig et al.
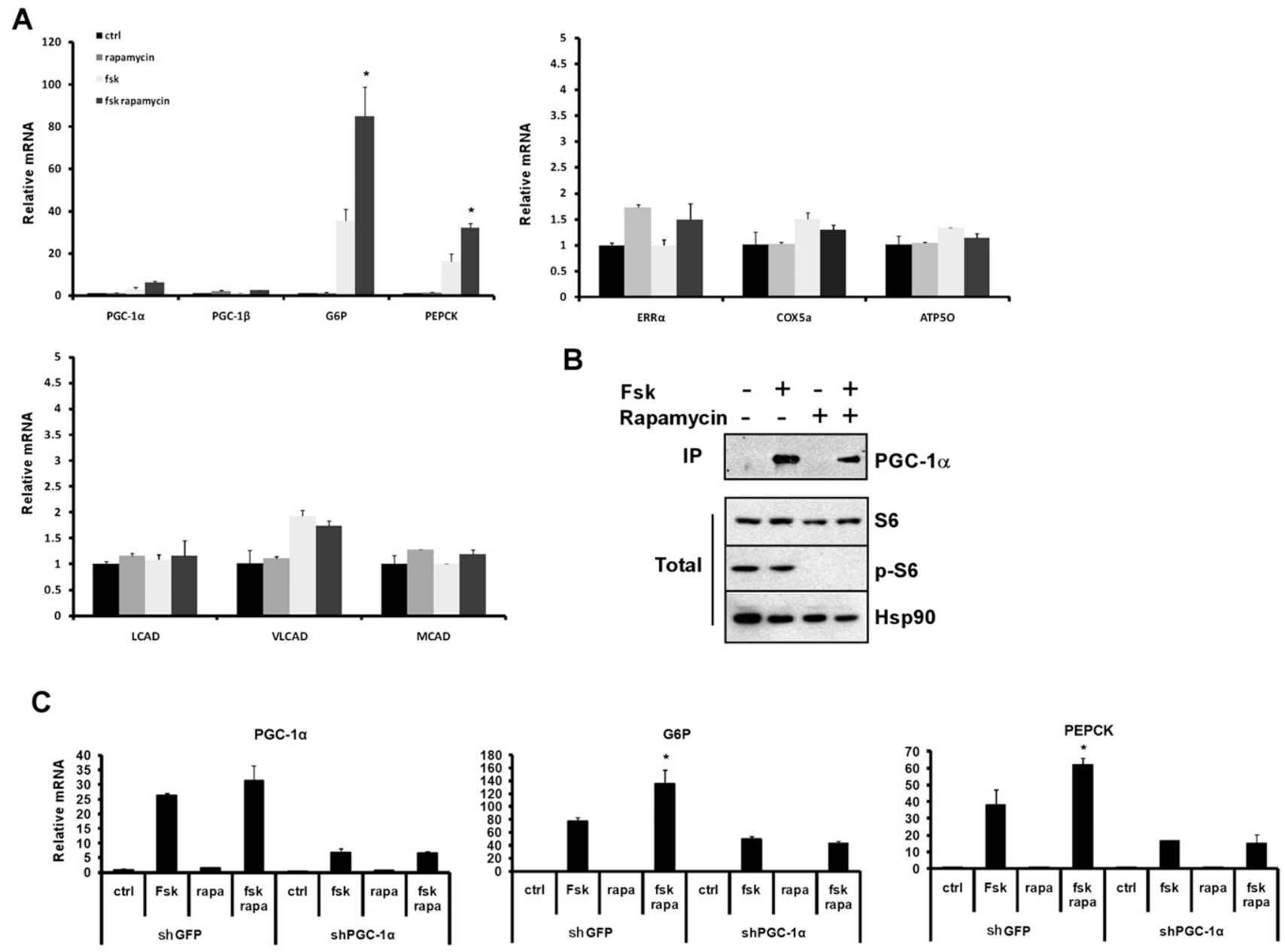

Figure 5. S6K1 action on gluconeogenesis is dependent on PGC-1 $\alpha$. Primary hepatocytes were treated with vehicle, $10 \mu M$ forskolin (Fsk) for 4 h, 20 nM rapamycin for 8 h, or Fsk/rapamycin before RNA and protein were extracted. (A) RNA was subjected to qRT-PCR analysis for the indicated genes. $(B)$ Endogenous PGC- $1 \alpha$ was immunoprecipitated from whole-cell extract using anti PGC-1 $\alpha$ antibodies. Total proteins and immunoprecipitated material were subjected to Western blot analysis using the indicated antibodies. $(C)$ Primary hepatocytes infected with adenoviral vectors expressing shGFP or shPGC- $1 \alpha$ were treated as in $A$. Total RNA was extracted and subjected to qRT-PCR analysis for the genes indicated. $\left(^{\star}\right) P<0.05$.

cells with S6K1 modulation. As seen in Figure 7A, wildtype PGC- $1 \alpha$ coimmunoprecipitates with $\mathrm{HNF} 4 \alpha$ under basal conditions when S6K1 is active. Blocking S6K1 signaling by rapamycin increases the interaction between $\mathrm{HNF} 4 \alpha$ and wild-type PGC- $1 \alpha$. Interestingly, the mutant PGC-1 $\alpha$ had increased binding to HNF4 $\alpha$ compared with wild-type PGC-1 $\alpha$, even under basal conditions; treatment with rapamycin did not further increase this interaction. In addition, expression of S6K1ca significantly attenuates the binding of HNF4 $\alpha$ to wild-type PGC-1 $\alpha$ but not to the mutant PGC- $1 \alpha$ (Fig. 7B).

We next tested the binding between PGC-1 $\alpha$ and FOXO1, which is coactivated by PGC-1 $\alpha$ and is also important for the regulation of gluconeogenesis. As shown in Figure 7C, blocking S6K1 activity with rapamycin did not enhance the binding of PGC- $1 \alpha$ to a constitutively activated mutant of FOXO1 (FOXO1 AAA).

To investigate the functional consequence of the differential binding of PGC- $1 \alpha$ to HNF4 $\alpha$ under S6K1 modula- tion, we performed luciferase-based transcriptional reporter assays. As expected, wild-type PGC- $1 \alpha$ strongly activates the HNF4 $\alpha$ gAF-1 response element (Rhee et al. 2003). Coexpression of S6K1ca repressed PGC-1 $\alpha$ activity (Fig. 7D). The mutant PGC- $1 \alpha$ had increased activation compared with wild-type PGC-1 $\alpha$, but coexpression of S6K1 had no effect on the activation of the HNF $4 \alpha$ gAF-1 response element (Fig. 7D). These data suggest that the binding of $\mathrm{HNF} 4 \alpha$ to PGC- $1 \alpha$ is modulated through the S6K1mediated phosphorylations at Ser 568/572. As a result, S6K1 phosphorylation represses the PGC-1 $\alpha$ coactivation on $\mathrm{HNF} 4 \alpha$.

The fatty acid oxidation program in the liver can be mediated through interactions between PGC- $1 \alpha$ and $\operatorname{PPAR} \alpha$, while PGC- $1 \alpha$ binding to $\mathrm{ERR} \alpha$ is critical in mitochondrial biogenesis (Vega et al. 2000; Schreiber et al. 2004). In contrast to what was seen above with $\mathrm{HNF} 4 \alpha$, the wild-type and mutant PGC-1 $\alpha$ interact similarly with both PPAR $\alpha$ and ERR $\alpha$ under basal conditions. In addition, no 
A

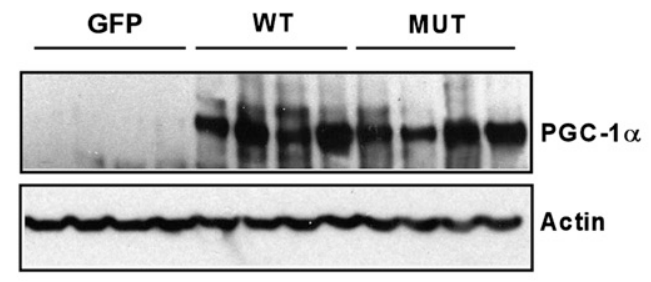

B
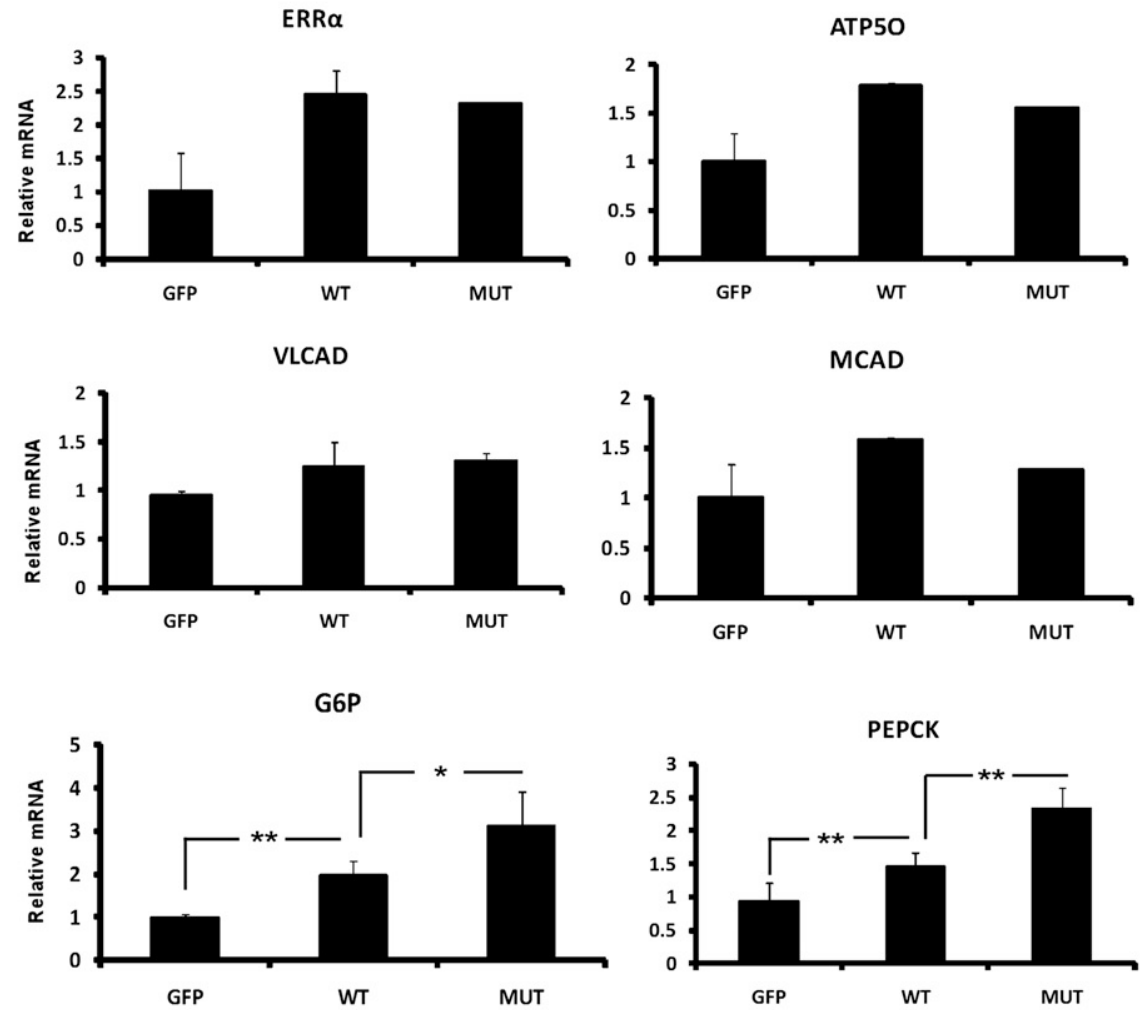

C

D
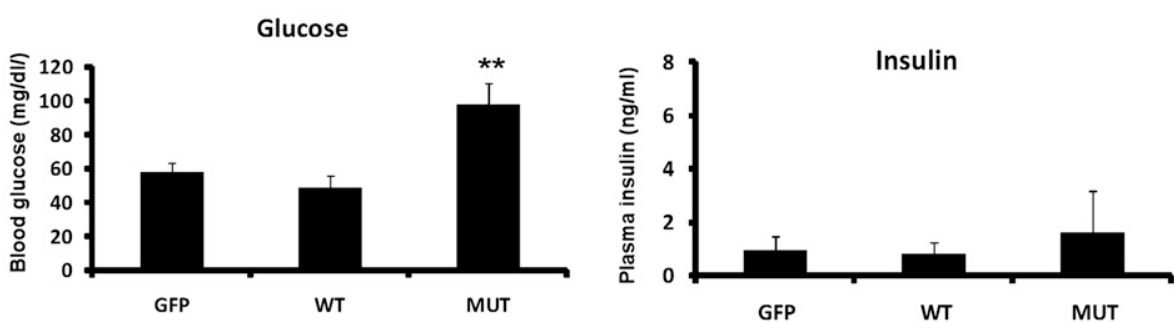

Figure 6. Mutation of the S6K1 PGC-1 $\alpha$ phosphorylation sites increases gluconeogenesis in vivo. Lean mice were injected with adenoviral vectors expressing GFP, wild-type PGC- $1 \alpha$ (WT), or mutant PGC-1 $\alpha$ (MUT). After $5 \mathrm{~d}$, the mice were fasted for $22 \mathrm{~h}$ and sacrificed. (A) PGC-1 $\alpha$ protein in the liver $(n=4)$, as determined by Western blot analysis. Actin was used as a loading control. $(B)$ Expression of mRNAs encoding gluconeogenic, mitochondrial, and fatty acid oxidation genes in the liver $(n=4-5)$, as determined by qRT-PCR analysis. $(C)$ Blood glucose levels $(n=4-5)$. $(D)$ Plasma insulin levels $(n=4-5) .\left(^{\star}\right) P<0.05 ;\left(^{\star \star}\right) P<0.01$.

increase in binding to either factor is observed when S6K1 signaling is blocked with rapamycin (Fig. 7E,F). Taken together, these data strongly suggest that S6K1 differentially suppresses gluconeogenesis through PGC-1 $\alpha$, at least in part, by modifying its ability to bind to HNF4 $\alpha$. The inability of S6K1 to regulate the binding of PGC-1 $\alpha$ to FOXO1, PPAR $\alpha$, and $\operatorname{ERR} \alpha$ further emphasizes the pathway specificity of this post-translational modification. 
Lustig et al.

A
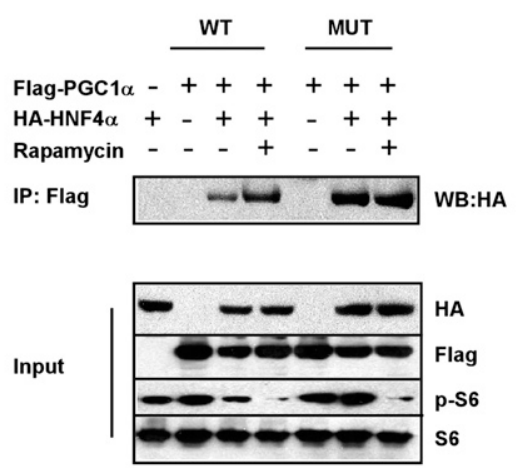

C

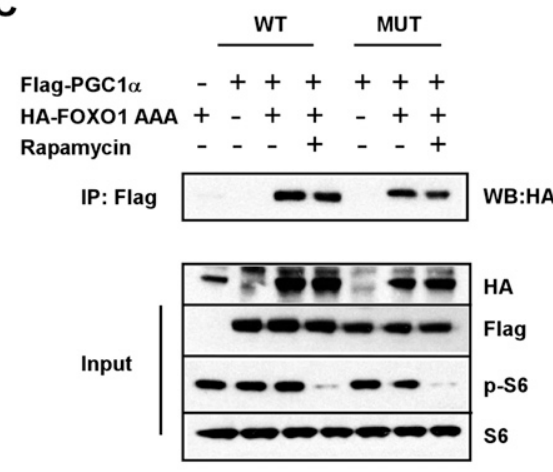

E
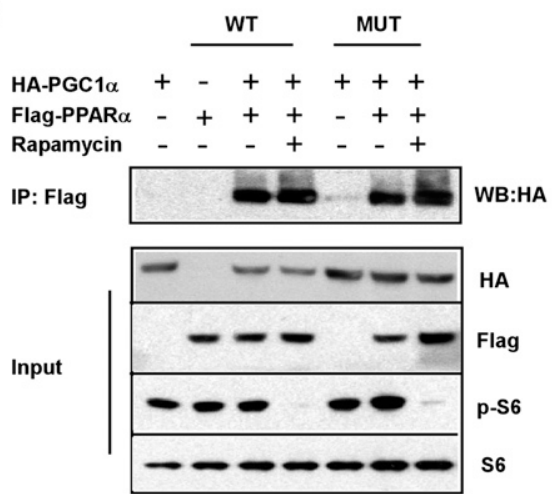

B

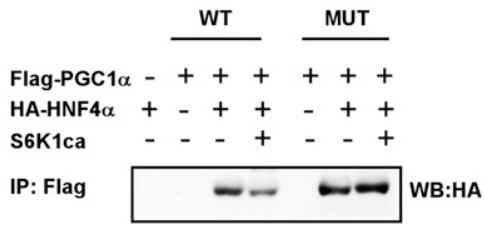

Input

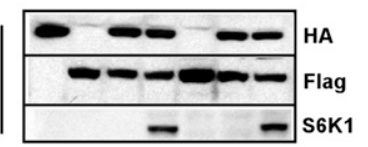

D

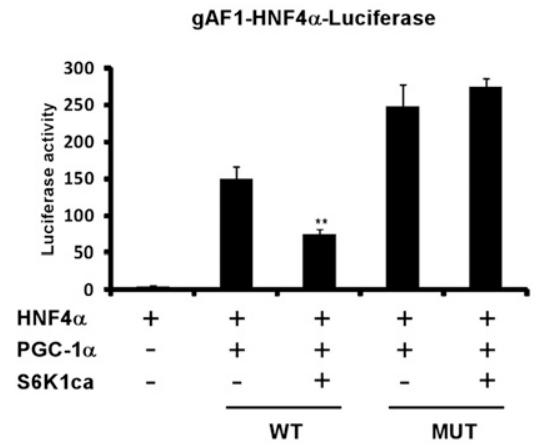

F

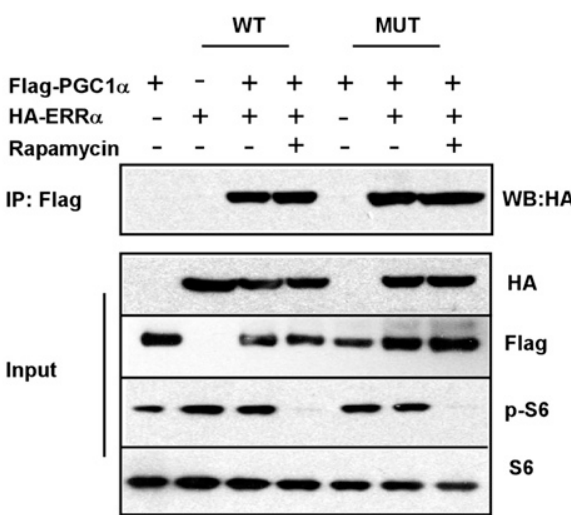

Figure 7. S6K1 activity affects the binding of PGC- $1 \alpha$ to HNF4 $\alpha$ but not to FOXO1, PPAR $\alpha$, or ERR $\alpha$. $(A, C, E, F)$ Cultured HEK293T cells were transfected with plasmids as indicated. Cells were treated for $90 \mathrm{~min}$ with vehicle or rapamycin before harvesting. Total lysates from transfected cells were subjected to immunoprecipitation using antibody beads specific for the Flag epitope. Both lysates and precipitates were analyzed by immunoblotting with the indicated antibodies. $(B)$ HEK293T cells were transfected with Flag-tagged PGC- $1 \alpha$ and HA-tagged HNF4 $\alpha$, with or without S6K1ca. Cells were incubated with serum and amino acid-free medium $2 \mathrm{~h}$ before harvesting. Total lysates were subjected to immunoprecipitation and Western blotting as in $A$. $(D)$ The indicated plasmids were transfected into HEK293T cells together with gAF1-luiferase reporter, and a luciferase assay was preformed as described in the Materials and Methods.

\section{Discussion}

Transcriptional control at the coactivator level is an effective way to link together biological pathways, and this mode of regulation has profound kinetic implications. Specifically, end-product production can be accelerated while ensuring that potentially toxic intermediates do not build up (for review, see Spiegelman and Heinrich
2004). PGC-1 $\alpha$ was among the first coactivators shown to be highly regulated in a large number of biological contexts, and is especially important in programs involving oxidative metabolism. Mitochondrial biogenesis and respiration, muscle fiber type switching, hepatic gluconeogenesis, fatty acid oxidation, and heme biosynthesis have all been shown to be affected by the levels of PGC-1 $\alpha$ (for review, see Lin et al. 2005). The activation of these complex programs is 
carried out by binding to and coactivation of many nuclear receptors and a large number of transcription factors outside the nuclear receptor family. However, since organisms are subject to changes in both external and internal conditions, it seems likely that there will be mechanisms whereby the linkage of gene programs through a coactivator such as PGC-1 $\alpha$ can be uncoupled. The data shown here illustrate the first such programmatic uncoupling through modification of the PGC- $1 \alpha$ protein.

PGC- $1 \alpha$ is strongly induced in the fasted liver, where it activates most or all of the hepatic gene programs associated with fasting: gluconeogenesis, heme biosynthesis, fatty acid oxidation, and mitochondrial electron transport (Herzig et al. 2001; Yoon et al. 2001; Puigserver et al. 2003; Rhee et al. 2003; Koo et al. 2004; Handschin et al. 2005; Wu et al. 2009). The linkage of these programs makes sense metabolically, as the fasted liver will use lipid oxidation in the mitochondria to generate all of the ATP necessary to provide the rest of the body with glucose via gluconeogenesis. Although this is classic physiology of fasting, it is easy to imagine that the fed state might sometimes require an uncoupling of hepatic gluconeogenesis from fatty acid oxidation. For example, a high-carbohydrate diet might provide sufficient glucose so that continued hepatic gluconeogenesis would be unnecessary or even cause hyperglycemia. Yet, if such a diet did not provide an overall adequate supply of calories, continued $\beta$-oxidation of fatty acids released by the adipose tissues might still be required to maintain ordinary hepatic functions.

S6K1 is a serine/threonine kinase that participates in a variety of intracellular signaling events, including mRNA translation, gene transcription, and cell cycle control. Insulin and certain nutrients, such as amino acids, are known to increase the phosphorylation and activation of S6K1(Um et al. 2006). Chronic rapamycin treatment in rats was shown to cause insulin resistance and glucose intolerance, in part through inducing the expression of the gluconeogenic enzymes PEPCK and G6Pase and PGC-1 $\alpha$ (Houde et al. 2010). We show here that S6K1 modifies PGC-1 $\alpha$ on two residues (568 and 572), and that these phosphorylations affect PGC- $1 \alpha$ in a highly specific way. Whereas overall protein and mRNA levels are unaffected, the ability of PGC-1 $\alpha$ to positively control gluconeogenesis is attenuated. Importantly, this occurs without any apparent change in other major hepatic gene programs controlled by PGC-1 $\alpha$ : mitochondrial electron transport and fatty acid oxidation. At least a significant part of this effect can be ascribed to the ability of these phosphorylations to negatively affect the binding of PGC- $1 \alpha$ to HNF $4 \alpha$, a nuclear receptor whose interaction with PGC-1 $\alpha$ is absolutely required for gluconeogenic gene expression (Rhee et al. 2003). The binding of HNF4 $\alpha$ to PGC-1 $\alpha$ has been shown to require multiple domains in the PGC-1 $\alpha$ protein, including the canonical LXXLL domains near the $\mathrm{N}$ terminus. However, previous data had also suggested the involvement of the RS domain, where the S6K1 phosphorylations take place (Puigserver et al. 2003). Thus, it is likely that these phosphorylations sterically hinder the physical interaction between PGC-1 $\alpha$ and HNF4 $\alpha$. However, it is also possible that this disruption involves additional proteins. Both AKT and Clk2 have been shown to directly phosphorylate PGC- $1 \alpha$ on the RS domain and mediate insulin responsiveness ( $\mathrm{Li}$ et al. 2007; Rodgers et al. 2010). However, these phosphorylations on PGC-1 $\alpha$ appear to reduce the overall coactivation function of PGC-1 $\alpha$ (Li et al. 2007; Rodgers et al. 2010). The data shown here provide for the first time a mechanism by which multiple functions of PGC-1 $\alpha$ are regulated independently.

The role of S6K1 in controlling PGC-1 $\alpha$ in other tissues is not known, but such a connection could be important in the energy metabolism of the malignant state. S6K1 is elevated in many cancers (Vogt 2001) and PGC-1 $\alpha$ expression is altered in several tumor types (Jeninga et al. 2010). The loss of oxidative metabolism in tumors has been observed for decades (Warburg effect), so it is not far-fetched to consider a role for S6K1 and PGC-1 $\alpha$ in this. The ability of signal transduction pathways to dissect the broad programs induced by PGC-1 $\alpha$ now seems clear.

\section{Materials and methods}

Creation of cDNA expression plasmids and adenoviruses

Full-length mouse PGC-1 $\alpha$ was amplified by PCR from a soleus cDNA library and cloned into pcDNA 3.1 (Invitrogen) in-frame with a Flag coding sequence. HA-PGC- $1 \alpha$ and Flag-PPAR $\alpha$ plasmids have been described previously (Lerin et al. 2006; Choi et al. 2010). HA-HNF4 $\alpha$ was cloned from a CMV-HNF4 $\alpha$ construct (Yoon et al. 2001) into pcDNA 3.1 and an HA tag was added. Mutant HA-PGC- $1 \alpha$ and mutant Flag-PGC- $1 \alpha$ were generated by in vitro mutagenesis (Stratagene) and sequenced. S6K1 and S6K1ca plasmids were a gift from John Blenis (Harvard Medical School, Boston, MA). HA-FOXO1 AAA plasmid was a gift from Keyong Du. The shPGC- $1 \alpha$ adenovirus (5'-GGTGGA TTGAAGTGGTGTAGA-3') was a gift from Marc Montminy. Adenoviruses for mouse wild-type and mutant Flag-PGC-1 $\alpha$ were created by using the pAd-Track-CMV/Ad-Easy adenoviral vector system (Stratagene), according to the manufacturer's instructions. Adenoviruses expressing S6K1ca and S6K1 DN were created as described (Ono et al. 2008).

\section{Primary hepatocyte isolation}

Primary mouse hepatocytes were isolated by collagen perfusion and percoll gradient purification. Eight-week-old to 12 -wk-old mice were euthanized with isofluorane immediately before the procedure. The liver was perfused with warm Hank's buffered saline supplemented with $0.4 \mathrm{~g} / \mathrm{L} \mathrm{KCl}, 1.0 \mathrm{~g} / \mathrm{L}$ glucose, $2.1 \mathrm{~g} / \mathrm{L}$ $\mathrm{NaHCO}_{3}$, and $0.2 \mathrm{~g} / \mathrm{L}$ EDTA (pH 7.4, $42^{\circ} \mathrm{C}$, CellGro) via the inferior vena cava. The portal vein was severed to allow drainage. Perfusion was continued with warmed Liver Digest Medium $\mathrm{pH}$ $7.4,42^{\circ} \mathrm{C}$; Invitrogen). Dissected liver was manually disrupted in DMEM supplemented with $10 \%$ FBS, $4.5 \mathrm{~g} / \mathrm{L}$ glucose, $2 \mathrm{mM}$ sodium pyruvate, $1 \mu \mathrm{M}$ dexamethasone (Sigma), $0.1 \mu \mathrm{M}$ insulin (Sigma), and penicillin/streptomycin (plating medium). The cell suspension was filtered $(70 \mu \mathrm{M})$ and viable hepatocytes were isolated after resuspension of pelleted cells in plating medium:PBS-buffered Percoll (Sigma) (1:1) and centrifugation at $800 \mathrm{rpm}$ for $5 \mathrm{~min}$. The cell pellet was washed two times with plating medium before seeding $\left(45,000\right.$ cells $\left./ \mathrm{cm}^{2}\right)$ in collagencoated plates. Two hours after seeding, the medium was changed to DMEM supplemented with $0.2 \%$ BSA, $4.5 \mathrm{~g} / \mathrm{L}$ glucose, $2 \mathrm{mM}$ sodium pyruvate, $0.1 \mu \mathrm{M}$ dexamethasone, $1 \mathrm{nM}$ insulin, and penicillin/streptomycin (maintenance medium). 


\section{Glucose output assay}

Primary mouse hepatocytes were seeded in six-well plates in plating medium. The next day, cells were transduced with adenoviruses expressing GFP, wild-type, and mutant PGC-1 $\alpha$ diluted in maintenance medium. Forty-eight hours after transduction, cells were washed three times with PBS and incubated in $1 \mathrm{~mL}$ per well of phenol red-free, glucose-free DMEM containing 1 $\mu \mathrm{M}$ Dex and $2 \mathrm{mM}$ pyruvate. Medium was collected $3 \mathrm{~h}$ later and subjected to glucose measurement using the Amplex Red Glucose/Glucose Oxidase Assay kit (Invitrogen). Cells were lysed, and protein concentration was determined for each lysate. The glucose output rate was normalized by cellular protein content.

\section{RNA isolation and quantitative RT-PCR ( $q R T-P C R$ )}

RNA from frozen tissue or cultured cells was reverse-transcribed and quantified with the Applied Biosystems Real-Time PCR system, SYBR Green PCR master mix, and the $\Delta \Delta$ Ct threshold cycle method. Gene expression levels were normalized to HPRT mRNA and expressed relative to control levels. Primer sequences are listed in Supplemental Table 1.

\section{In vitro phosphorylation analysis}

GST-PGC- $1 \alpha$ fragments from wild type and mutant (generated by in vitro mutagenesis) (Stratagene) were expressed in bacteria (BL21 strain; Novagen) and purified using glutathione agarose beads. Recombinant proteins were used as a substrate for in vitro phosphorylation reaction with activated S6K1 (BioVision), AKT (Cell Signaling), and PKA (Calbiochem) using the manufacturers' instructions. After phosphorylation reaction, glutathione beads were washed extensively and analyzed by SDS-PAGE and autoradiography. Protein levels were monitored by Coomassie blue staining.

\section{Animal experiments}

All animal experiments conformed to protocols approved by the animal care and use committee at the Dana-Farber Cancer Institute. Experiments were performed in 6- to 8-wk-old male $\mathrm{BALB} / \mathrm{c}$ mice. Animals were fed a standard rodent chow in a controlled environment with a 14- to 10-h light-dark cycle. Control, GFP, wild-type, and mutant PGC- $1 \alpha$ adenoviruses $(1 \times$ $10^{9}$ infectious adenovirus particles per mouse) were delivered intravenously to mice. Mice were killed 6-8 d following adenoviral transduction. Blood was obtained at time of sacrifice. Livers were extracted and immediately snap-frozen on liquid nitrogen and stored at $-80^{\circ} \mathrm{C}$ until analysis.

\section{Cell culture, adenoviral infections, and coimmunoprecipitations}

HEK293T cells were grown in DMEM supplemented with 10\% FBS. For adenoviral overexpression and knockdown studies, primary hepatocytes were infected $1 \mathrm{~d}$ after isolation with the indicated adenovirus diluted in maintenance medium. Sixteen hours post-infection, cells were incubated in medium lacking insulin and dexamethasone for an additional $24 \mathrm{~h}$. Cells were treated with rapamycin (Cell Signaling) and forskolin (Sigma) for the time indicated. For coimmunoprecipitation experiments, cells were transfected with Lipofectamine 2000 (Invitrogen) with the indicated plasmids. Forty-eight hours after transfection, cells were lysed in $\mathrm{M} 2$ lysis buffer $(50 \mathrm{mM}$ Tris- $\mathrm{HCl}$ at $\mathrm{pH} 7.8,137$ $\mathrm{mM} \mathrm{NaCl}, 10 \mathrm{mM}$ NaF, $1 \mathrm{mM}$ EDTA, 1\% Triton X-100, 0.2\% sarkosyl, $1 \mathrm{mM} \mathrm{DTT,} \mathrm{10 \%} \mathrm{glycerol)} \mathrm{containing} \mathrm{protease} \mathrm{and}$ phosphatase inhibitors. Five-hundred micrograms of total protein was subjected to immunoprecipitation with an M2 agarose anti-Flag resin (Sigma) for $3 \mathrm{~h}$ at $4^{\circ} \mathrm{C}$. Proteins were separated by SDS-PAGE, blotted, and incubated with anti-HA and anti-Flag antibodies.

\section{Protein isolation and Western blotting}

Liver proteins were solubilized in radioimmunoprecipitation assay buffer (RIPA), and primary hepatocytes were solubilized in M2 lysis buffer containing protease and phosphatase inhibitors. PGC- $1 \alpha$ was immunoprecipitated from $1 \mathrm{mg}$ of (forskolinor rapamycin-treated) protein using an anti-PGC- $1 \alpha$ antibody. Protein samples were resolved by SDS-PAGE, blotted, and incubated with anti-PGC-1 $\alpha$ (gift from Dr. Thomas Gettys, Pennington Biomedical Research Center), phospho-S6 (Ser235/ 236), total S6 antibodies, or S6K1 (Cell Signaling). Equal loading was confirmed using anti-actin or $90-\mathrm{kDa}$ heat-shock protein.

\section{Transcriptional reporter assays}

HEK293T cells were transfected by Lipofectamine 2000 (Invitrogen). All transfection amounts were corrected with empty vector plasmid DNA. Cells were grown for $24 \mathrm{~h}$ post-transfection and harvested, and luciferase activities were determined by a luciferase assay kit (Promega).

\section{Statistical analysis}

Two-tailed Student's $t$-test was used to determine $P$-values. Statistical significance was defined as $P<0.05$ and $P<0.01$.

\section{Acknowledgments}

We thank John Blenis for the S6K1 and S6K1ca plasmids, and Keyong Du for the HA-FOXO1 AAA plasmid. Y.L. is supported by a post-doctoral fellowship from the International Human Frontier Science Program Organization. J.L.R. was supported in part by a grant from the Wenner-Gren Foundations (Sweden). J.L.E. was supported by a post-doctoral fellowship from the Canadian Institutes of Health Research and the H.L. Holmes Award for Post-doctoral Studies from the National Research Council of Canada. J.C.L. was supported by NIH grant T32 HL07604. This work was supported by NIH grants DK54477 and DK61562 to B.M.S.

\section{References}

Ajioka RS, Phillips JD, Kushner JP. 2006. Biosynthesis of heme in mammals. Biochim Biophys Acta 1763: 723-736.

Arany Z, Foo SY, Ma Y, Ruas JL, Bommi-Reddy A, Girnun G, Cooper M, Laznik D, Chinsomboon J, Rangwala SM, et al. 2008. HIF-independent regulation of VEGF and angiogenesis by the transcriptional coactivator PGC-1 $\alpha$. Nature 451: 1008-1012.

Baar K, Wende AR, Jones TE, Marison M, Nolte LA, Chen M, Kelly DP, Holloszy JO. 2002. Adaptations of skeletal muscle to exercise: rapid increase in the transcriptional coactivator PGC-1. FASEB J 16: 1879-1886.

Brown EJ, Albers MW, Shin TB, Ichikawa K, Keith CT, Lane WS, Schreiber SL. 1994. A mammalian protein targeted by G1arresting rapamycin-receptor complex. Nature 369: 756758.

Choi JH, Banks AS, Estall JL, Kajimura S, Bostrom P, Laznik D, Ruas JL, Chalmers MJ, Kamenecka TM, Bluher M, et al. 
2010. Anti-diabetic drugs inhibit obesity-linked phosphorylation of PPAR $\gamma$ by Cdk5. Nature 466: 451-456.

Estall JL, Ruas JL, Choi CS, Laznik D, Badman M, Maratos-Flier E, Shulman GI, Spiegelman BM. 2009. PGC-1 $\alpha$ negatively regulates hepatic FGF21 expression by modulating the heme/Rev-Erb $\alpha$ axis. Proc Natl Acad Sci 106: 22510-22515.

Fan M, Rhee J, St Pierre J, Handschin C, Puigserver P, Lin J, Jaeger S, Erdjument-Bromage $H$, Tempst $\mathrm{P}$, Spiegelman BM. 2004. Suppression of mitochondrial respiration through recruitment of p160 myb binding protein to PGC-1 $\alpha$ : modulation by p38 MAPK. Genes Dev 18: 278-289.

Finck BN, Kelly DP. 2006. PGC-1 coactivators: inducible regulators of energy metabolism in health and disease. I Clin Invest 116: 615-622.

Flotow H, Thomas G. 1992. Substrate recognition determinants of the mitogen-activated 70K S6 kinase from rat liver. J Biol Chem 267: 3074-3078.

Handschin C, Lin J, Rhee J, Peyer AK, Chin S, Wu PH, Meyer UA, Spiegelman BM. 2005. Nutritional regulation of hepatic heme biosynthesis and porphyria through PGC-1 $\alpha$. Cell 122: 505-515.

Herzig S, Long F, Jhala US, Hedrick S, Quinn R, Bauer A, Rudolph D, Schutz G, Yoon C, Puigserver P, et al. 2001. CREB regulates hepatic gluconeogenesis through the coactivator PGC-1. Nature 413: 179-183.

Houde VP, Brule S, Festuccia WT, Blanchard PG, Bellmann K, Deshaies Y, Marette A. 2010. Chronic rapamycin treatment causes glucose intolerance and hyperlipidemia by upregulating hepatic gluconeogenesis and impairing lipid deposition in adipose tissue. Diabetes 59: 1338-1348.

Jeninga EH, Schoonjans K, Auwerx J. 2010. Reversible acetylation of PGC-1: connecting energy sensors and effectors to guarantee metabolic flexibility. Oncogene 29: 4617-4624.

Knutti D, Kralli A. 2001. PGC-1, a versatile coactivator. Trends Endocrinol Metab 12: 360-365.

Koo SH, Satoh H, Herzig S, Lee CH, Hedrick S, Kulkarni R, Evans RM, Olefsky J, Montminy M. 2004. PGC-1 promotes insulin resistance in liver through PPAR- $\alpha$-dependent induction of TRB-3. Nat Med 10: 530-534.

Koves TR, Li P, An J, Akimoto T, Slentz D, Ilkayeva O, Dohm GL, Yan Z, Newgard CB, Muoio DM. 2005. Peroxisome proliferator-activated receptor- $\gamma$ co-activator $1 \alpha$-mediated metabolic remodeling of skeletal myocytes mimics exercise training and reverses lipid-induced mitochondrial inefficiency. J Biol Chem 280: 33588-33598.

Lelliott CJ, Medina-Gomez G, Petrovic N, Kis A, Feldmann HM, Bjursell M, Parker N, Curtis K, Campbell $\mathrm{M}, \mathrm{Hu}$, et al. 2006. Ablation of PGC-1 $\beta$ results in defective mitochondrial activity, thermogenesis, hepatic function, and cardiac performance. PLOS Biol 4: e369. doi: 10.1371/journal.pbio. 0040369.

Leone TC, Lehman JJ, Finck BN, Schaeffer PJ, Wende AR, Boudina S, Courtois M, Wozniak DF, Sambandam N, BernalMizrachi C, et al. 2005. PGC-1 $\alpha$ deficiency causes multisystem energy metabolic derangements: muscle dysfunction, abnormal weight control and hepatic steatosis. PLOS Biol 3: e101. doi: 10.1371/journal.pbio.0030101.

Lerin C, Rodgers JT, Kalume DE, Kim SH, Pandey A, Puigserver P. 2006. GCN5 acetyltransferase complex controls glucose metabolism through transcriptional repression of PGC- $1 \alpha$. Cell Metab 3: 429-438.

Li X, Monks B, Ge Q, Birnbaum MJ. 2007. Akt/PKB regulates hepatic metabolism by directly inhibiting PGC-1 $\alpha$ transcription coactivator. Nature 447: 1012-1016.

Lin J, Wu H, Tarr PT, Zhang CY, Wu Z, Boss O, Michael LF, Puigserver P, Isotani E, Olson EN, et al. 2002. Transcriptional co-activator PGC-1 $\alpha$ drives the formation of slow-twitch muscle fibres. Nature 418: 797-801.

Lin J, Wu PH, Tarr PT, Lindenberg KS, St Pierre J, Zhang CY, Mootha VK, Jager S, Vianna CR, Reznick RM, et al. 2004. Defects in adaptive energy metabolism with CNS-linked hyperactivity in PGC-1 $\alpha$ null mice. Cell 119: 121-135.

Lin J, Handschin C, Spiegelman BM. 2005. Metabolic control through the PGC-1 family of transcription coactivators. Cell Metab 1: 361-370.

Mootha VK, Handschin C, Arlow D, Xie X, St Pierre J, Sihag S, Yang W, Altshuler D, Puigserver P, Patterson N, et al. 2004. Erro and Gabpa/b specify PGC- $1 \alpha$-dependent oxidative phosphorylation gene expression that is altered in diabetic muscle. Proc Natl Acad Sci 101: 6570-6575.

Nobukuni T, Joaquin M, Roccio M, Dann SG, Kim SY, Gulati P, Byfield MP, Backer JM, Natt F, Bos JL, et al. 2005. Amino acids mediate $\mathrm{mTOR} /$ raptor signaling through activation of class 3 phosphatidylinositol 3OH-kinase. Proc Natl Acad Sci 102: $14238-14243$.

Norrbom J, Sundberg CJ, Ameln H, Kraus WE, Jansson E, Gustafsson T. 2004. PGC-1 $\alpha$ mRNA expression is influenced by metabolic perturbation in exercising human skeletal muscle. J Appl Physiol 96: 189-194.

Ono H, Pocai A, Wang Y, Sakoda H, Asano T, Backer JM, Schwartz GJ, Rossetti L. 2008. Activation of hypothalamic S6 kinase mediates diet-induced hepatic insulin resistance in rats. J Clin Invest 118: 2959-2968.

Patti ME, Brambilla E, Luzi L, Landaker EJ, Kahn CR. 1998. Bidirectional modulation of insulin action by amino acids. J Clin Invest 101: 1519-1529.

Pearce LR, Komander D, Alessi DR. 2010. The nuts and bolts of AGC protein kinases. Nat Rev Mol Cell Biol 11: 9-22.

Pearson RB, Dennis PB, Han JW, Williamson NA, Kozma SC, Wettenhall RE, Thomas G. 1995. The principal target of rapamycin-induced p70s6k inactivation is a novel phosphorylation site within a conserved hydrophobic domain. EMBO J 14: 5279-5287.

Puigserver P, Wu Z, Park CW, Graves R, Wright M, Spiegelman BM. 1998. A cold-inducible coactivator of nuclear receptors linked to adaptive thermogenesis. Cell 92: 829-839.

Puigserver P, Rhee J, Lin J, Wu Z, Yoon JC, Zhang CY, Krauss S, Mootha VK, Lowell BB, Spiegelman BM. 2001. Cytokine stimulation of energy expenditure through p38 MAP kinase activation of PPAR $\gamma$ coactivator-1. Mol Cell 8: 971982.

Puigserver P, Rhee J, Donovan J, Walkey CJ, Yoon JC, Oriente F, Kitamura Y, Altomonte J, Dong H, Accili D, et al. 2003. Insulin-regulated hepatic gluconeogenesis through FOXO1PGC-1 $\alpha$ interaction. Nature 423: 550-555.

Rhee J, Inoue Y, Yoon JC, Puigserver P, Fan M, Gonzalez FJ, Spiegelman BM. 2003. Regulation of hepatic fasting response by PPAR $\gamma$ coactivator- $1 \alpha$ (PGC-1): requirement for hepatocyte nuclear factor $4 \alpha$ in gluconeogenesis. Proc Natl Acad Sci 100: 4012-4017.

Rodgers JT, Puigserver P. 2007. Fasting-dependent glucose and lipid metabolic response through hepatic sirtuin 1. Proc Natl Acad Sci 104: 12861-12866.

Rodgers JT, Lerin C, Haas W, Gygi SP, Spiegelman BM, Puigserver P. 2005. Nutrient control of glucose homeostasis through a complex of PGC-1 $\alpha$ and SIRT1. Nature 434: 113-118.

Rodgers JT, Haas W, Gygi SP, Puigserver P. 2010. Cdc2-like kinase 2 is an insulin-regulated suppressor of hepatic gluconeogenesis. Cell Metab 11: 23-34.

Schreiber SN, Emter R, Hock MB, Knutti D, Cardenas J, Podvinec M, Oakeley EJ, Kralli A. 2004. The estrogenrelated receptor $\alpha(\mathrm{ERR} \alpha)$ functions in PPAR $\gamma$ coactivator $1 \alpha$ 
Lustig et al.

(PGC-1 $\alpha$ )-induced mitochondrial biogenesis. Proc Natl Acad Sci 101: 6472-6477.

Spiegelman BM, Heinrich R. 2004. Biological control through regulated transcriptional coactivators. Cell 119: 157-167.

Um SH, D'Alessio D, Thomas G. 2006. Nutrient overload, insulin resistance, and ribosomal protein S6 kinase 1, S6K1. Cell Metab 3: 393-402.

Vega RB, Huss JM, Kelly DP. 2000. The coactivator PGC-1 cooperates with peroxisome proliferator-activated receptor $\alpha$ in transcriptional control of nuclear genes encoding mitochondrial fatty acid oxidation enzymes. Mol Cell Biol 20: 1868-1876.

Vianna CR, Huntgeburth M, Coppari R, Choi CS, Lin J, Krauss S, Barbatelli G, Tzameli I, Kim YB, Cinti S, et al. 2006. Hypomorphic mutation of PGC-1 $\beta$ causes mitochondrial dysfunction and liver insulin resistance. Cell Metab 4: 453-464.

Vogt PK. 2001. PI 3-kinase, mTOR, protein synthesis and cancer. Trends Mol Med 7: 482-484.

Wu Z, Puigserver P, Andersson U, Zhang C, Adelmant G, Mootha V, Troy A, Cinti S, Lowell B, Scarpulla RC, et al. 1999. Mechanisms controlling mitochondrial biogenesis and respiration through the thermogenic coactivator PGC-1. Cell 98: $115-124$.

Wu H, Kanatous SB, Thurmond FA, Gallardo T, Isotani E, Bassel-Duby R, Williams RS. 2002. Regulation of mitochondrial biogenesis in skeletal muscle by CaMK. Science 296: 349-352.

Wu N, Yin L, Hanniman EA, Joshi S, Lazar MA. 2009. Negative feedback maintenance of heme homeostasis by its receptor, Rev-erba. Genes Dev 23: 2201-2209.

Yoon JC, Puigserver P, Chen G, Donovan J, Wu Z, Rhee J, Adelmant G, Stafford J, Kahn CR, Granner DK, et al. 2001. Control of hepatic gluconeogenesis through the transcriptional coactivator PGC-1. Nature 413: 131-138.

Zechner C, Lai L, Zechner JF, Geng T, Yan Z, Rumsey JW, Collia D, Chen Z, Wozniak DF, Leone TC, et al. 2010. Total skeletal muscle PGC-1 deficiency uncouples mitochondrial derangements from fiber type determination and insulin sensitivity. Cell Metab 12: 633-642. 


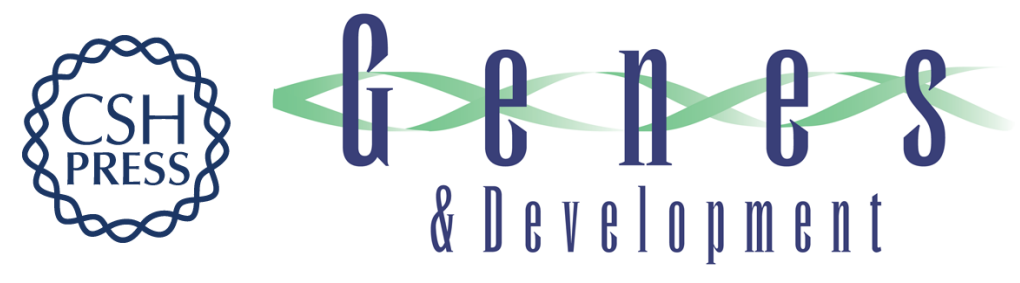

\section{Separation of the gluconeogenic and mitochondrial functions of PGC-1 $\alpha$ through S6 kinase}

Yaniv Lustig, Jorge L. Ruas, Jennifer L. Estall, et al.

Genes Dev. 2011, 25: originally published online June 6, 2011

Access the most recent version at doi:10.1101/gad.2054711

\section{Supplemental http://genesdev.cshlp.org/content/suppl/2011/06/02/gad.2054711.DC1 \\ Material}

Related Content

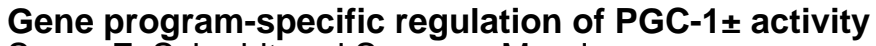

Søren F. Schmidt and Susanne Mandrup

Genes Dev. July , 2011 25: 1453-1458

References This article cites 48 articles, 13 of which can be accessed free at:

http://genesdev.cshlp.org/content/25/12/1232.full.html\#ref-list-1

Articles cited in:

http://genesdev.cshlp.org/content/25/12/1232.full.html\#related-urls

\section{License}

Email Alerting

Service

Receive free email alerts when new articles cite this article - sign up in the box at the top right corner of the article or click here.

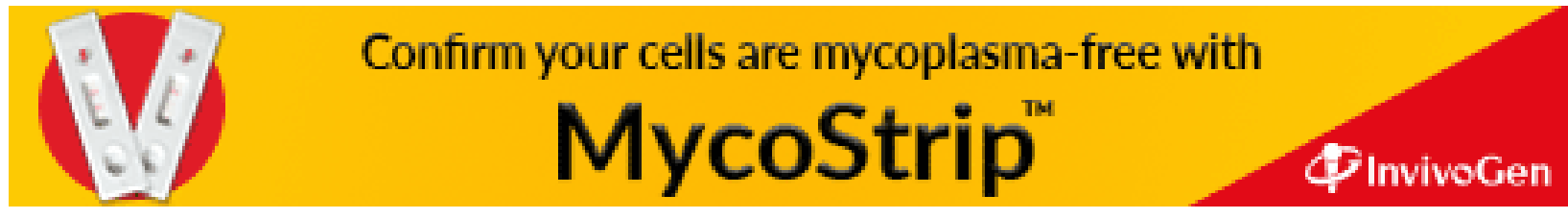

